\title{
PYCOEVOL:
}

\section{A Python workflow to study protein-protein coevolution}

Fábio Madeira and Ludwig Krippahl

CENTRIA-DI, Universidade Nova de Lisboa, Caparica, Portugal 
I. Background

2. Motivation

3. Implementation

4. Results

5. Conclusions

6. Future work 


\section{DPSLDRPFISEGTTLKDLIYDMTT}

Primary structure

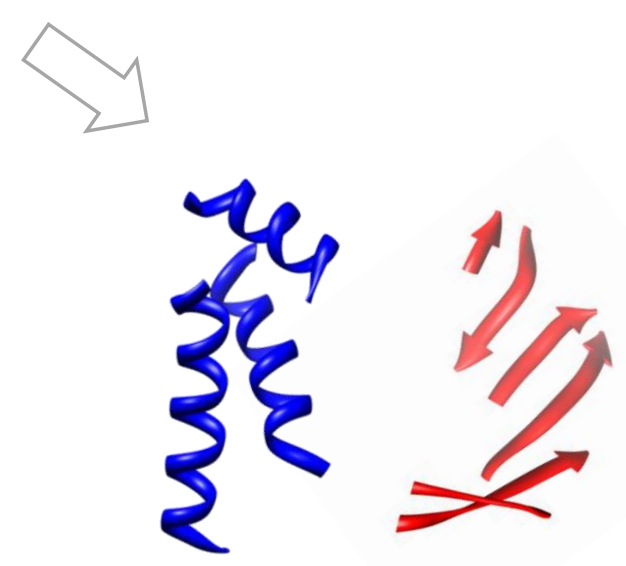

Secondary structure
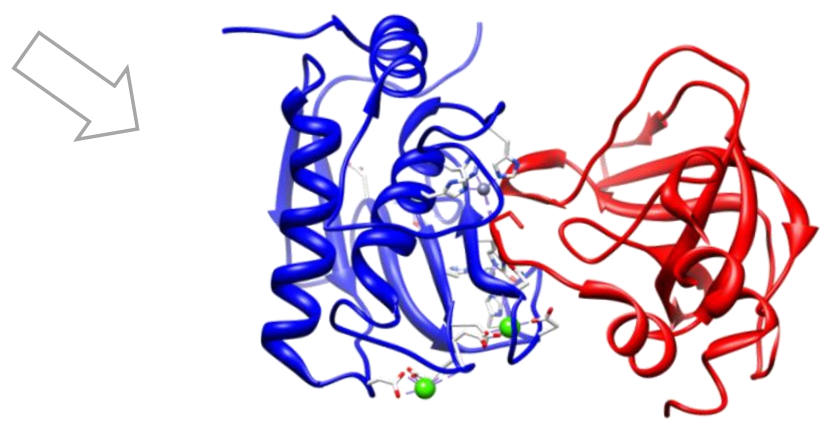

Tertiary/quaternary structure 
$>$ Co-adaptation or correlated mutations 
$>$ Co-adaptation or correlated mutations

$>$ Change of a biological object triggered by the change of a related object 
$>$ Co-adaptation or correlated mutations

$>$ Change of a biological object triggered by the change of a related object

$>$ Accumulation of structural and functional changes throughout lineages, imposed by evolutionary constraints 
$>$ Co-adaptation or correlated mutations

$>$ Change of a biological object triggered by the change of a related object

$>$ Accumulation of structural and functional changes throughout lineages, imposed by evolutionary constraints

$>$ Proposed to aid:

$>$ Protein folding and fold recognition

$>$ Prediction of protein-protein interactions [Pazos et al, 1997] 


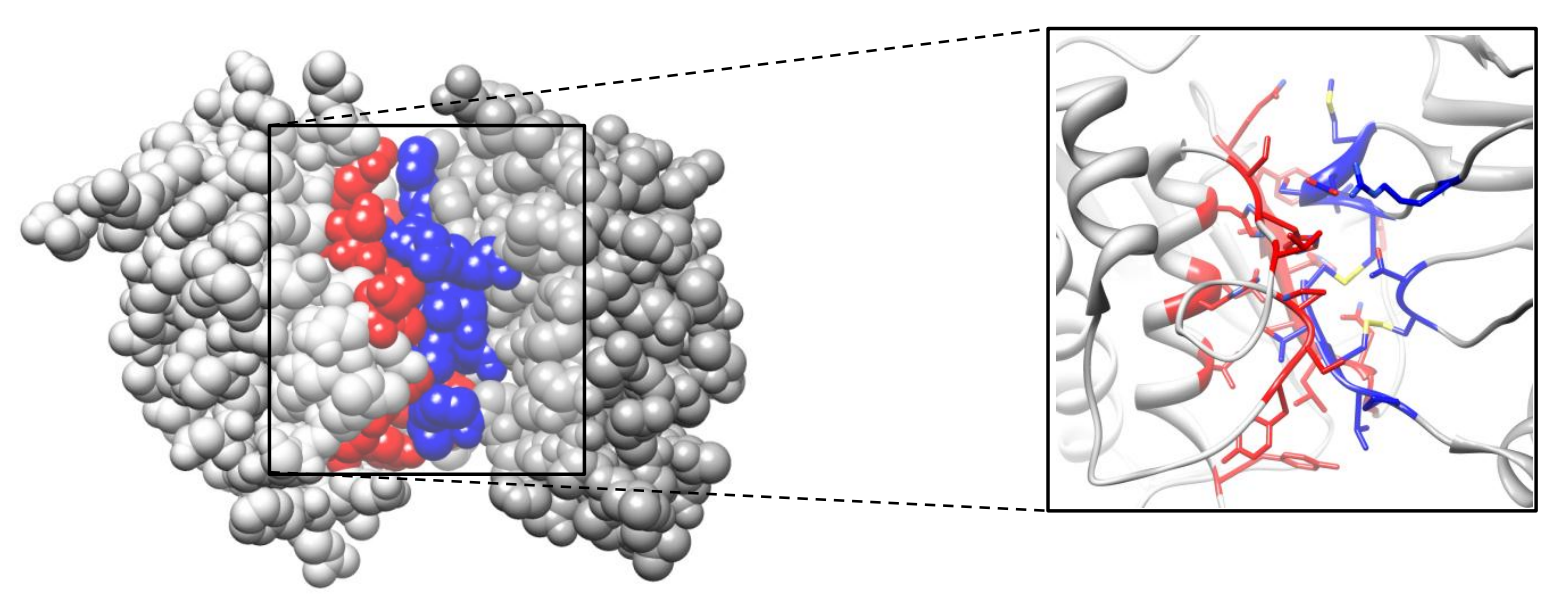

$>$ Interacting proteins have a key role in every biological process, and they have evolved performing mutual interactions 


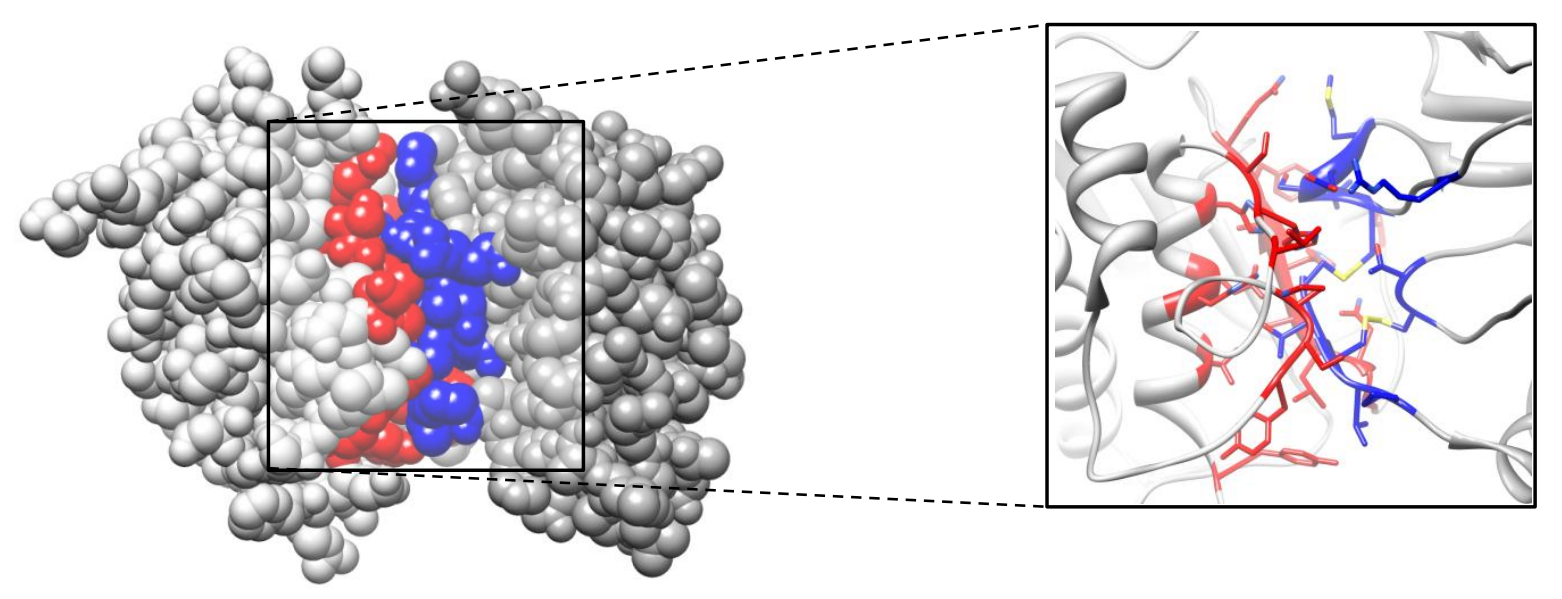

$>$ Interacting proteins have a key role in every biological process, and they have evolved performing mutual interactions

$>$ The sequence of an interacting protein must reflect the process of adaptation 
I. Search for homologous sequences
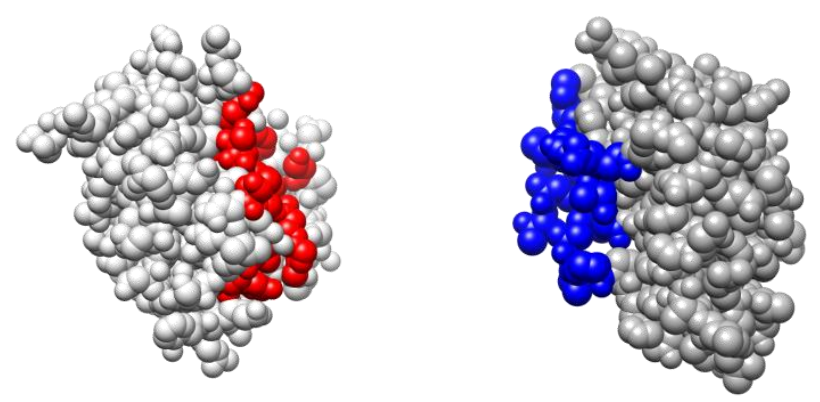
I. Search for homologous sequences

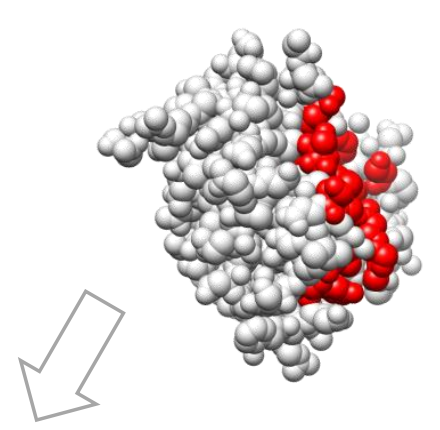

DPSLDRPFISEGTTLKDLIYDMTT

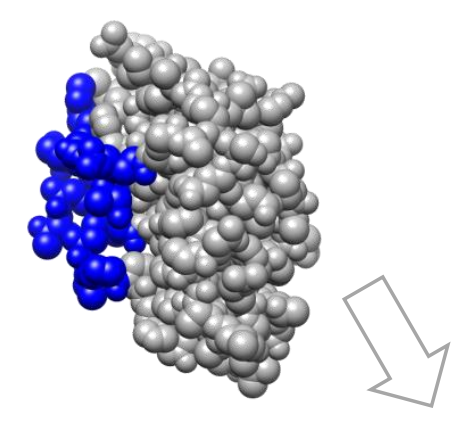

VEGMIKLALSTASGLAHLHME I 
I. Search for homologous sequences

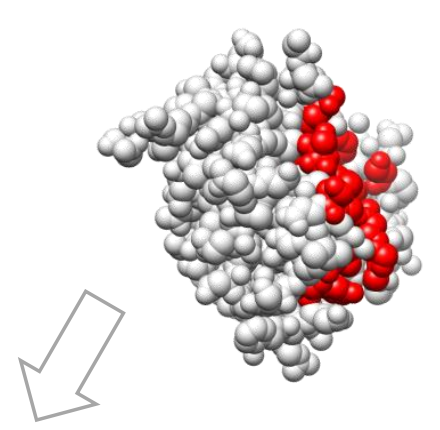

DPSLDRPFISEGTTLKDLIYDMTT

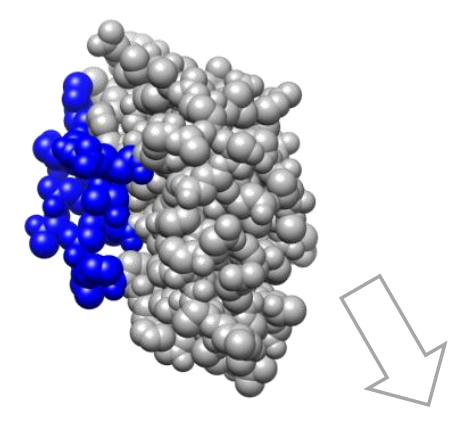

VEGMIKLALSTASGLAHLHME I

\section{MSA \\ computation}




\section{Search for homologous sequences}

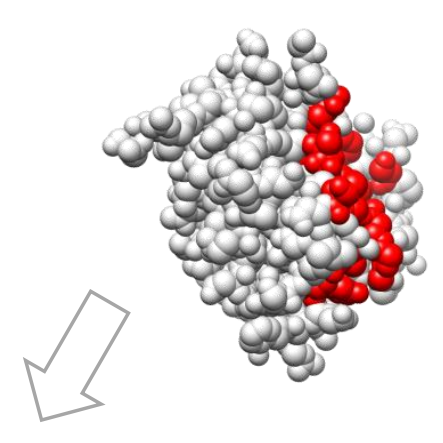

DPSLDRPEISEGTTLKDLIYDMTT

-- - - EPRPDSGRDWSVELQEL--

- - - KPGPDLGRDWSVELQEL--

- - - -EPESDSGRDWSAELPEL--

- - - EPEPGSGGDCSEELPEL--

- - - -DPEPGSGGDCSEELPEL--

PEPEQEPEPDSGGDCSAELPEL--

RKQGLHSMNMMEAACSEPSLDL--

\section{MSA computation}

VEGMIKLALSTASGLAHLHME I

WGSSLRMALSLAQGLAFLHEER WGSSLRMALSLAQGLAFLHEER WGSSLRMALSLAQGLAFLHEER WGSSLSMALSLAEGLAFLHGRR WGSSLSMALSLAEGLAFLHERR - -SSMSMALSLAQGLAFLHER - -SSCRLAHS ITRGLAYLHTRR 
I. Search for homologous sequences

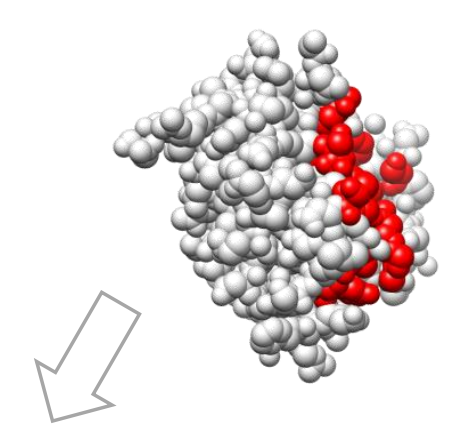

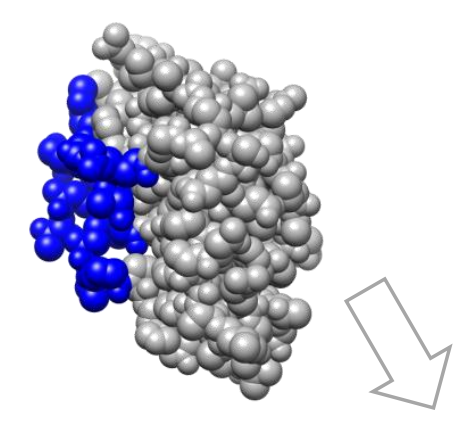

DPSLDRPFISEGTTLKDLIYDMTT

- - - EPRPDSGRDWSVELQEL--

- - - KPGPDLGRDWSVELQEL--

- - - -EPESDSGRDWSAELPEL--

- - - EPEPGSGGDCSEELPEL--

--- - DPEPGSGGDCSEELPEL--

PEPEQEPEPDSGGDCSAELPEL--

RKQGLHSMNMMEAACSEPSLDL--

\section{MSA} computation

3. Coevolution analysis

VEGMIKLALSTASGLAHLHME I

WGSSLRMALSLAQGLAFLHEER WGSSLRMALSLAQGLAFLHEER WGSSLRMALSLAQGLAFLHEER WGSSLSMALSLAEGLAFLHGRR WGSSLSMALS LAEGLAFLHERR - -SSMSMALS LAQGLAFLHER- -SSCRLAHS ITRGLAYLHTRR 
I. Search for homologous sequences
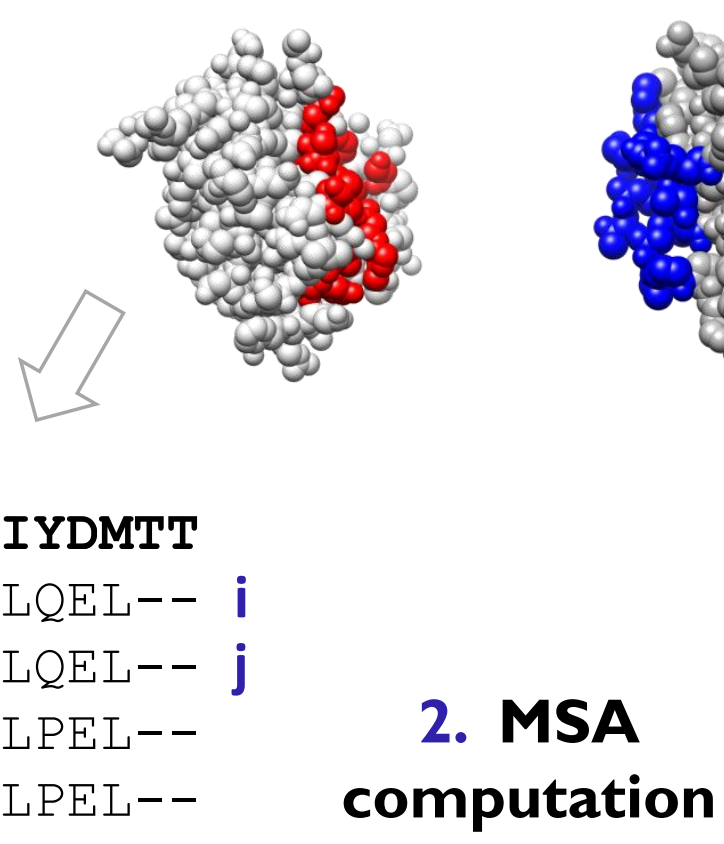

DPSLDRPEISEGTTLKDLIYDMTT

-- - -EPRPDSGRDWSVELQEL-- i

- - - - KPGPDLGRDWSVELQEL-- j

- - - EPESDSGRDWSAELPEL--

- - - EPEPGSGGDCSEELPEL--

-- - -DPEPGSGGDCSEELPEL--

PEPEQEPEPDSGGDCSAELPEL--

RKQGLHSMNMMEAACSEPSLDL--

$\mathrm{x}$

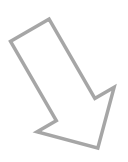

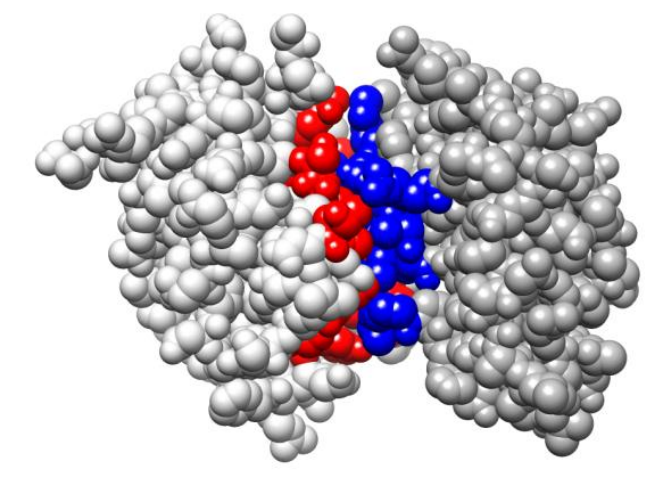

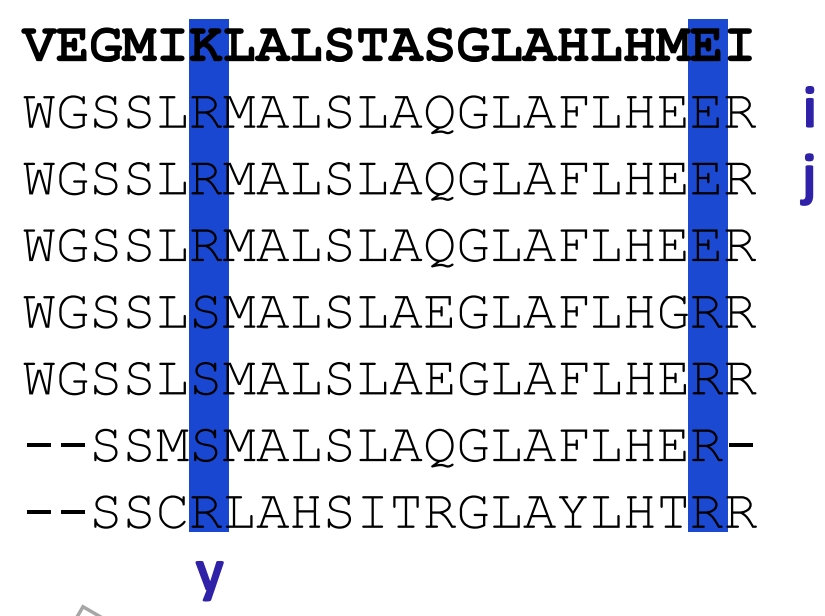

VEGMIRLALSTASGLAHLHMEI

WGSSLRMALSLAQGLAFLHEER i WGSSLRMALSLAQGLAFLHEER j WGSSLRMALSLAQGLAFLHE WGSSLSMALSLAEGLAFLHG WGSSLSMALSLAEGLAFLHE - SSMSMALSLAQGLAFLHE - - SSCRLAHS ITRGLAYLHTRR y

\section{Coevolution} analysis 
$>$ Matrix-based

$>\mathrm{CLM}, \mathrm{CPVN}$, VOL, etc.

$>$ Correlation-based

> Pearson, Spearman, McBASC, Quartets, OMES, etc.

$>$ Perturbation-based

$>\mathrm{MI}, \mathrm{SCA}, \mathrm{ELSC}$, etc.

$>$ Phylogenetic dependent

$>$ Mirrortree, etc. 
$>$ Large number of scoring functions 
$>$ Large number of scoring functions

$>$ There is no benchmark or survey on the accuracy of each method 
$>$ Large number of scoring functions

$>$ There is no benchmark or survey on the accuracy of each method

$>$ Most of these methods are not available to the community 

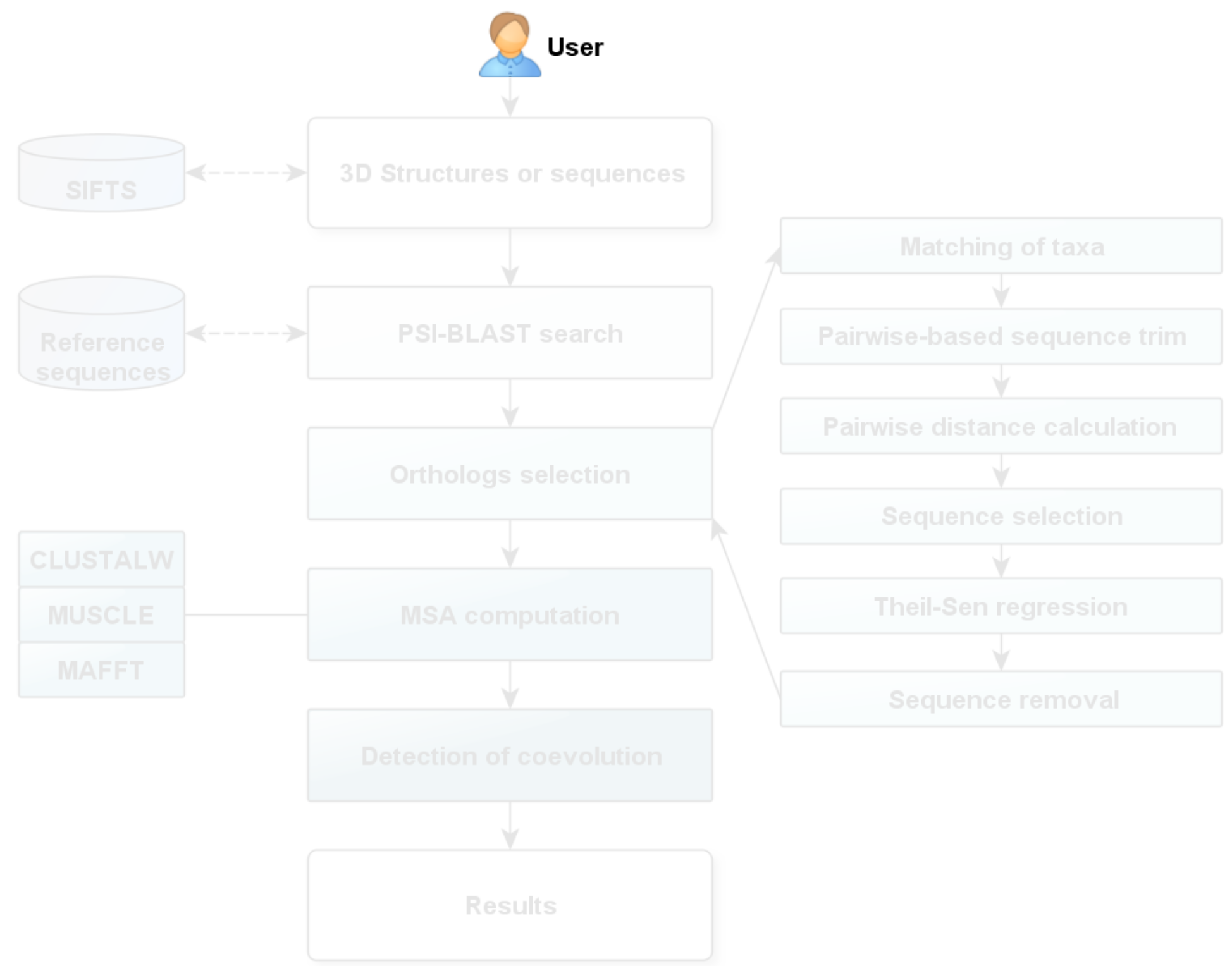

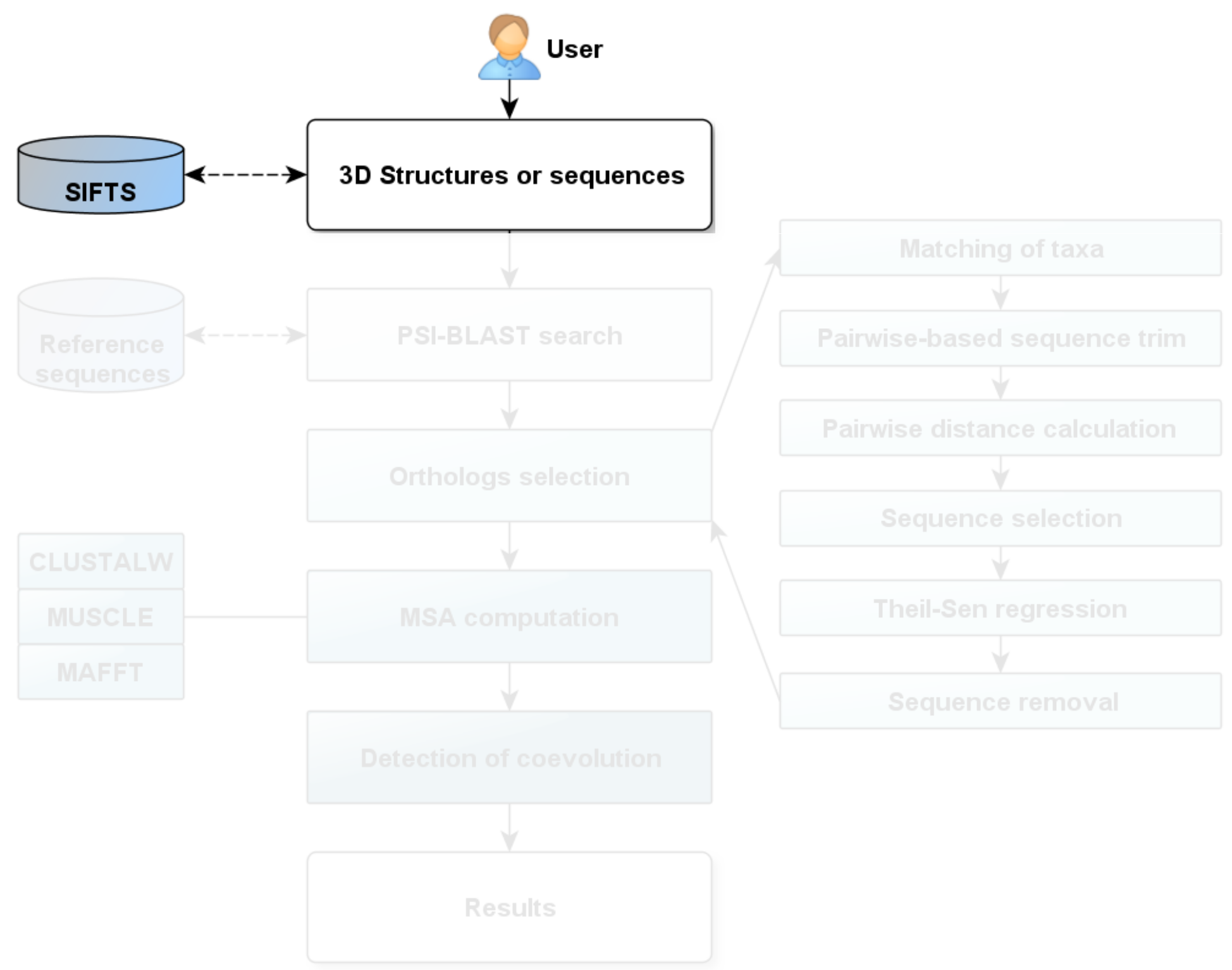

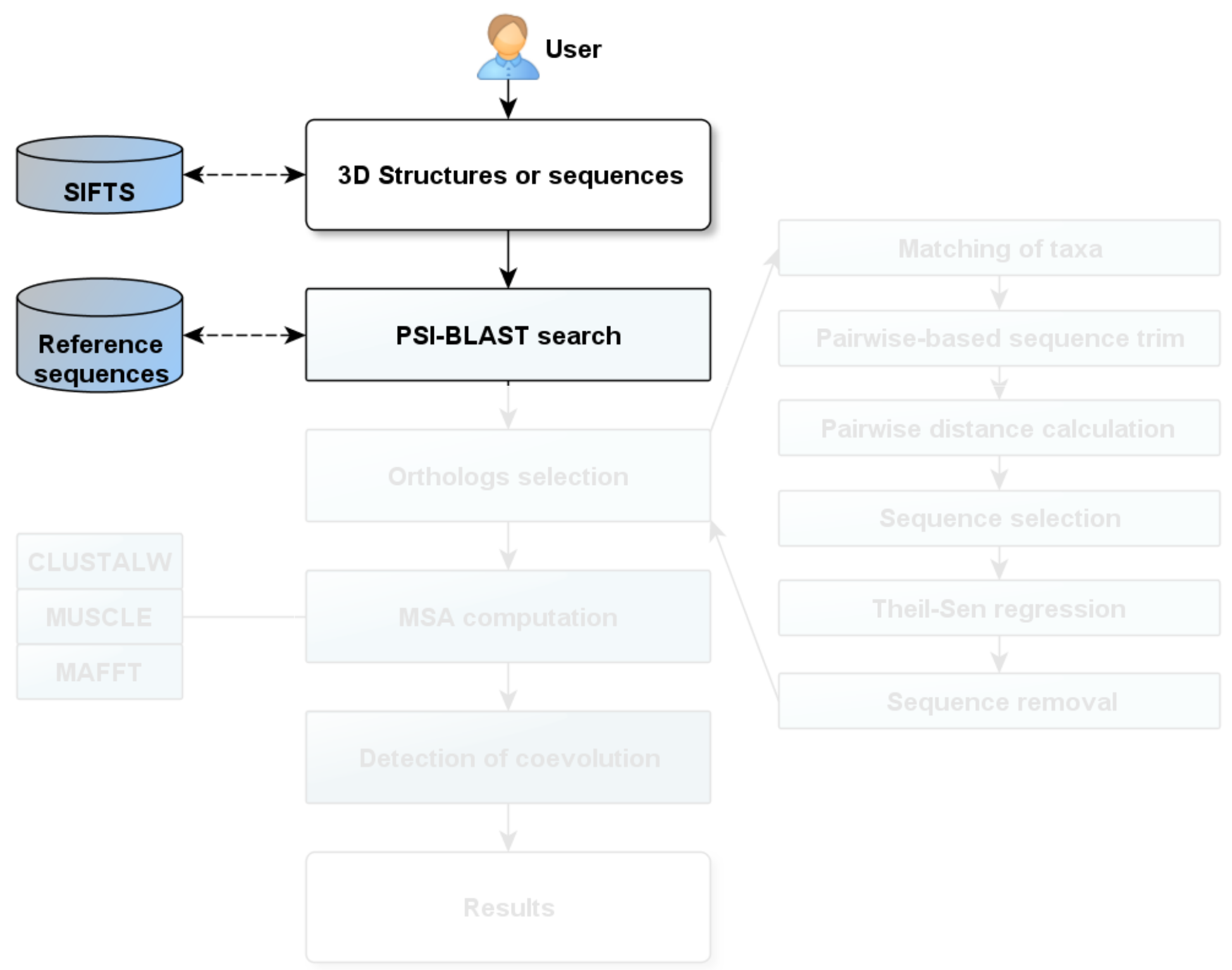


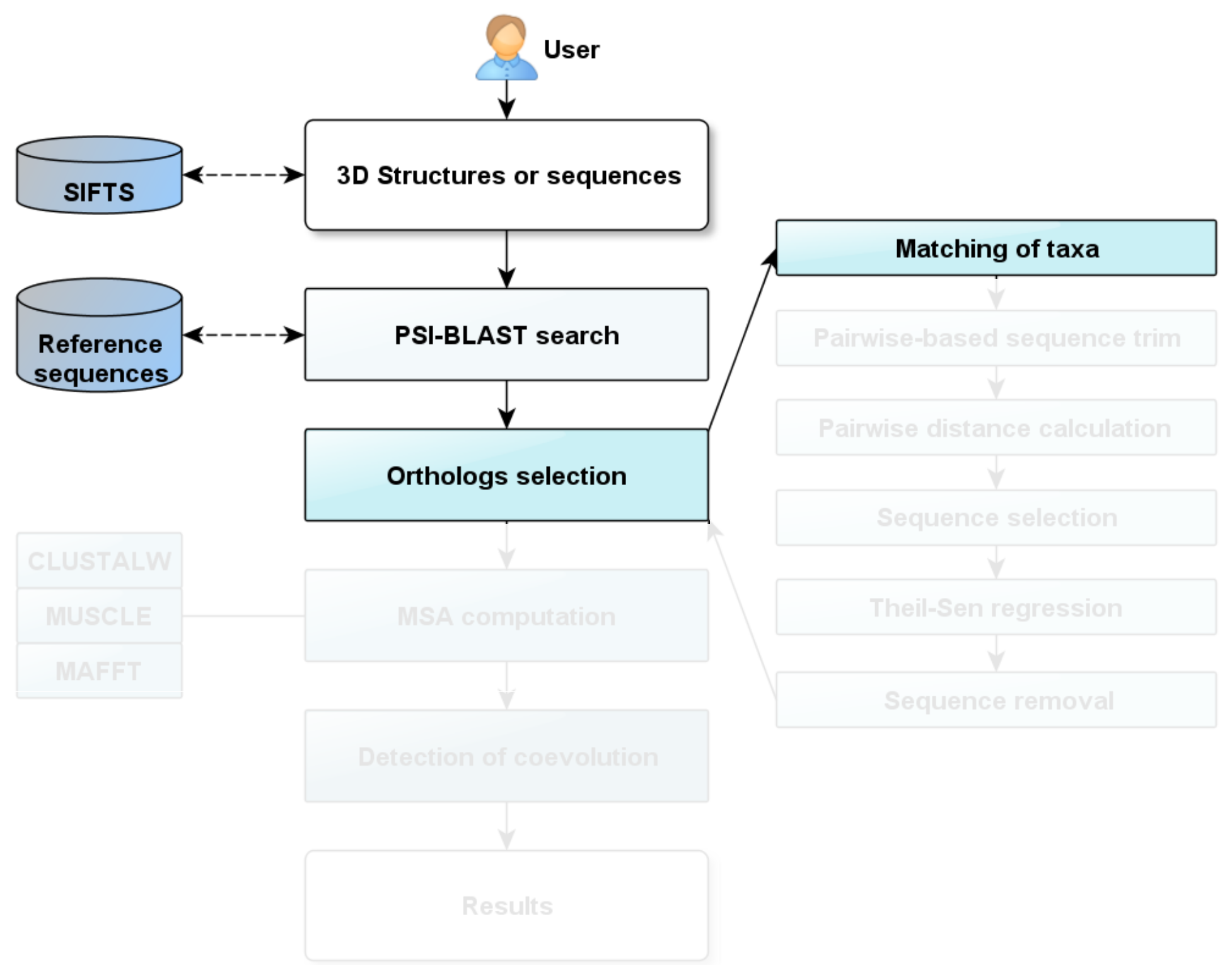




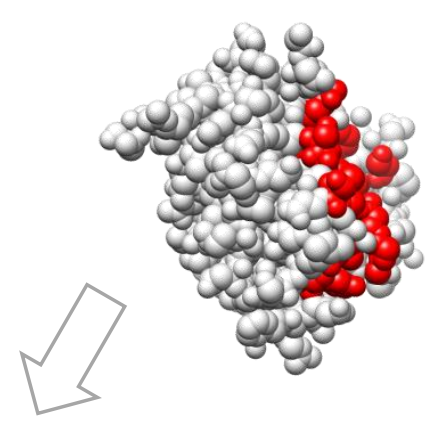

Organism1 Organism2 Organism3 Organism 4 Organism5 Organism 6 Organism 7 Organism 8
DPSLDRPFISEGTTLKDLIYDMTT -----EPRPDSGRDWSVELQEL------KPGPDLGRDWSVELQEL-- - - EPESDSGRDWSAELPEL-- - - EPEPGSGGDCSEELPEL------DPEPGSGGDCSEELPEL-PEPEQEPEPDSGGDCSAELPEL-RKQGLHSMNMMEAACSEPSLDL--

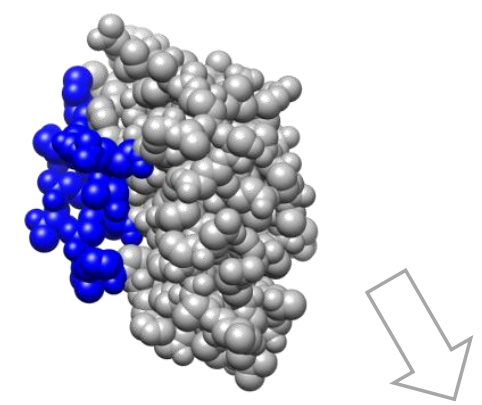

Organism3 VEGMIKLALSTASGLAHLHMEI Organism1 WGSSLRMALSLAQGLAFLHEER Organism9 WGSSLRMALSLAQGLAFLHEER Organism8 WGSSLRMALSLAQGLAFLHEER Organism5 WGSSLSMALSLAEGLAFLHGRR Organism10 WGSSLSMALSLAEGLAFLHERR Organism2 --SSMSMALSLAQGLAFLHEROrganism11 --SSCRLAHSITRGLAYLHTRR 


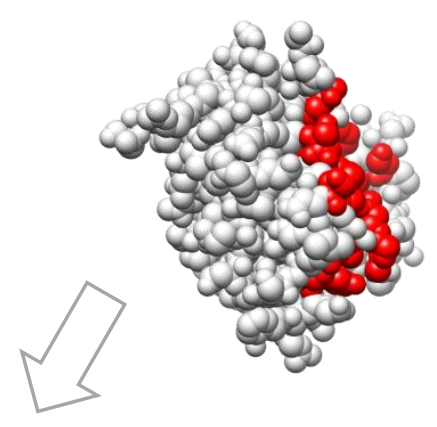

Organism1 DPSLDRPFISEGTTLKDLIYDMTT Organism2 -----EPRPDSGRDWSVELQEL-Organism3 -----KPGPDLGRDWSVELQEL-Organism4 -----EPESDSGRDWSAELPEL-Organism5 -----EPEPGSGGDCSEELPEL-Organism6 -----DPEPGSGGDCSEELPEL-Organism7 PEPEQEPEPDSGGDCSAELPEL-Organism8 RKQGLHSMNMMEAACSEPSLDL--

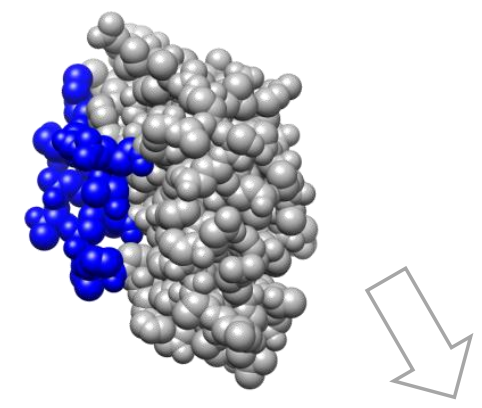

Organism3 VEGMIKLALSTASGLAHLHMEI Organism1 WGSSLRMALSLAQGLAFLHEER Organism9 WGSSLRMALSLAQGLAFLHEER Organism8 WGSSLRMALSLAQGLAFLHEER Organism5 WGSSLSMALSLAEGLAFLHGRR Organism10 WGSSLSMALSLAEGLAFLHERR Organism2 --SSMSMALSLAQGLAFLHEROrganism11 --SSCRLAHSITRGLAYLHTRR 


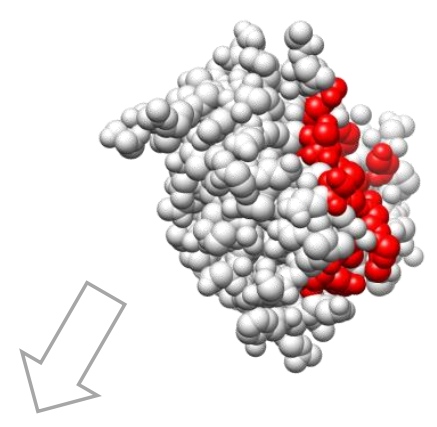

Organism1 DPSLDRPFISEGTTLKDLIYDMTT Organism2 -----EPRPDSGRDWSVELQEL-Organism3 -----KPGPDLGRDWSVELQEL-Organism4 --_-EPESDSGRDHSAEIPEI-Organism5 -----EPEPGSGGDCSEELPEL-Organism6 - - DPPPGSGGDCSEEIPEI-Organism7 PEPEQEPEPDSGCDCSAEIPEI-Organism8 RKQGLHSMNMMEAACSEPSLDL--

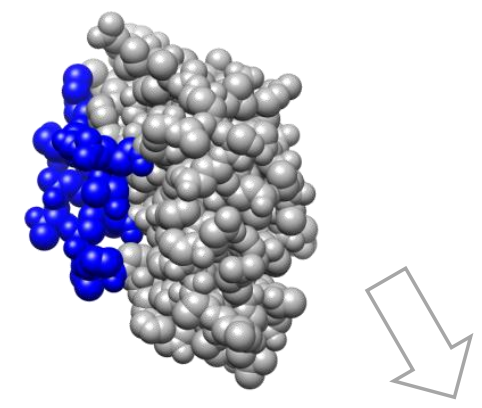

Organism3 VEGMIKLALSTASGLAHLHMEI Organism1 WGSSLRMALSLAQGLAFLHEER Organism9 NGSSIRMAISIAQGIAEIHEER Organism8 WGSSLRMALSLAQGLAFLHEER Organism5 WGSSLSMALSLAEGLAFLHGRR Organism10 HGSSISMAISIAEGIAFIHERR Organism2 --SSMSMALSLAQGLAFLHEROrganism11 -SSCRIAHSITRGIAYIHTRR 


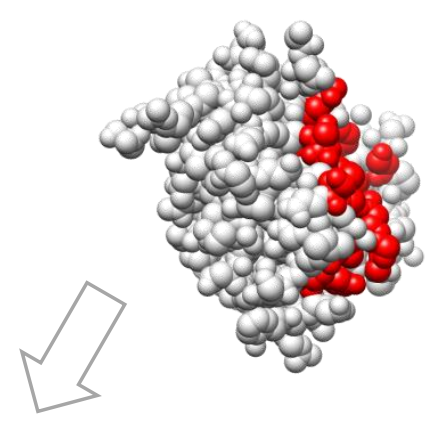

Organism1 Organism2 Organism3 Organism4 Organism5 Organism6 Organism7 Organism8

DPSLDRPFISEGTTLKDLIYDMTT -----EPRPDSGRDWSVELQEL------KPGPDLGRDWSVELQEL-----EPESDSGRDWSAEIPEI-- - - EPEPGSGGDCSEELPEL- - - DPEPGSGGDCSEEIPEIPEPEQEPEPDSGCDCSAEIPEI-RKQGLHSMNMMEAACSEPSLDL--<smiles>C1CC2CC1C2</smiles>

Organism1 Organism3 Organism2 Organism5 Organism8
DPSLDRPFISEGTTLKDLIYDMTT -----KPGPDLGRDWSVELQEL-- - - EPRPDSGRDWSVELQEL-- - - EPEPGSGGDCSEELPEL- RKQGLHSMNMMEAACSEPSLDL--

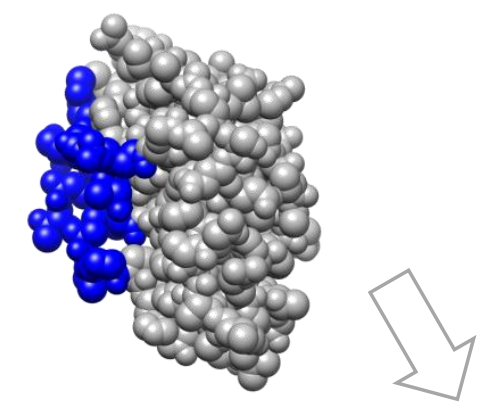

Organism3 Organism1 Organismg Organism8 Organism5 Organism10 Organism2 Organism11

VEGMIKLALSTASGLAHLHMEI WGSSLRMALSLAQGLAFLHEER WGSSIRMAISIAQGIAFIHEER WGSSLRMALSLAQGLAFLHEER WGSSLSMALSLAEGLAFLHGRR HGSSISMAISIAEGIAFIHERR - - SSMSMALSLAQGLAFLHER- SSCRIAHSITRGIAYIHTRR $\square$

Organism1 WGSSLRMALSLAQGLAFLHEER Organism3 VEGMIKLALSTASGLAHLHMEI Organism2 --SSMSMALSLAQGLAFLHEROrganism5 WGSSLSMALSLAEGLAFLHGRR Organism8 WGSSLRMALSLAQGLAFLHEER 


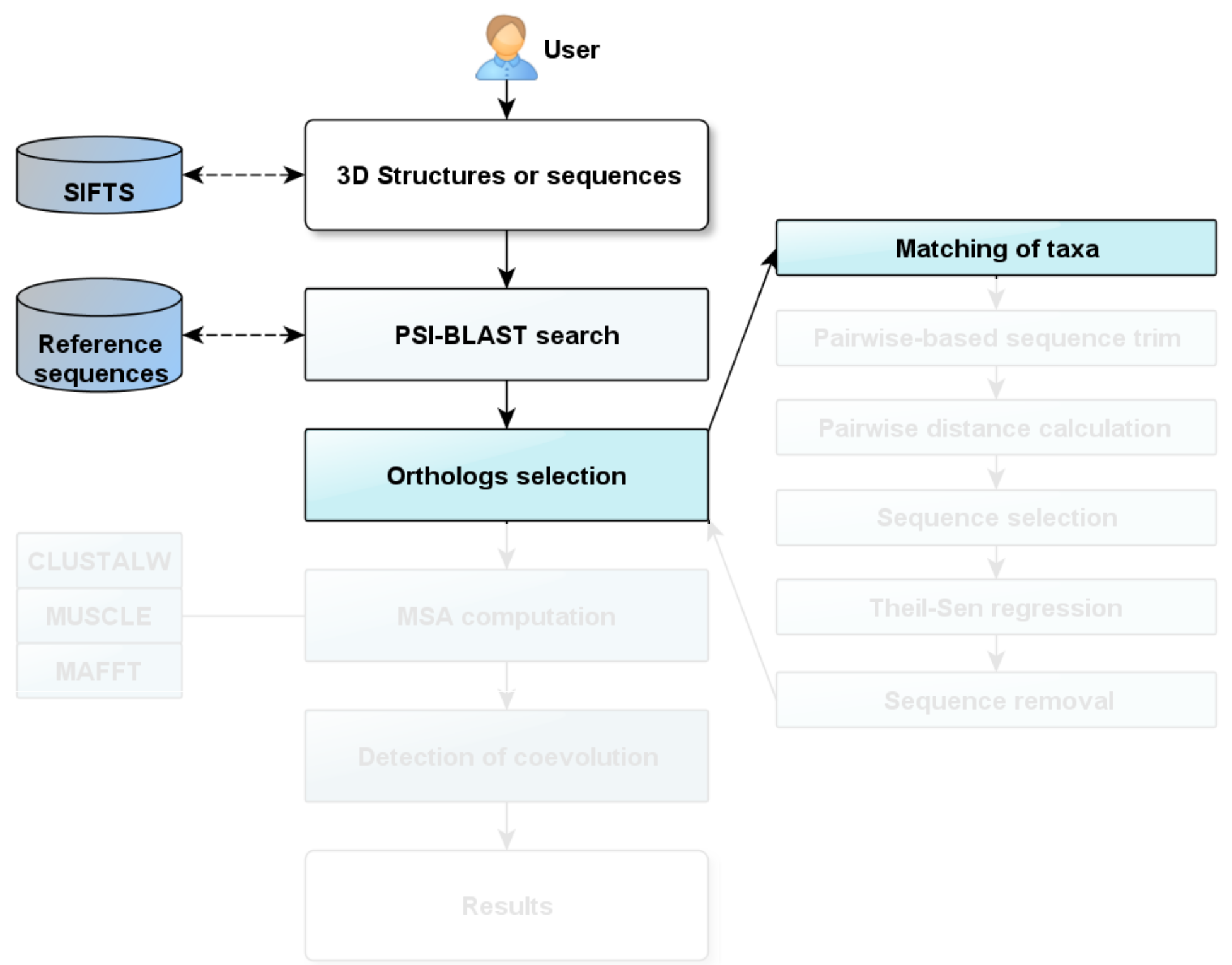




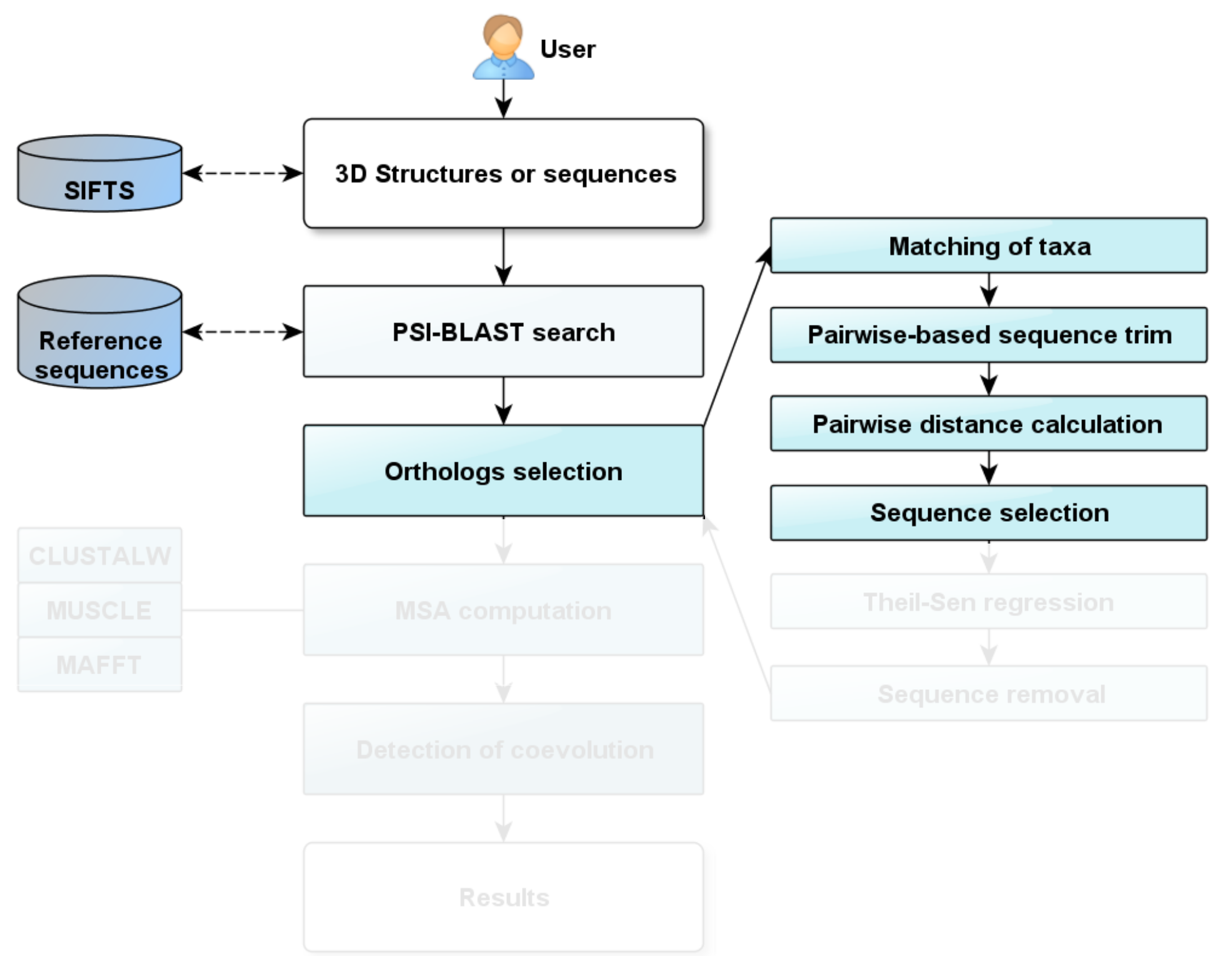


$>$ P-distance [Jukes and Cantor, 1969]

$$
d=p=\frac{N_{\text {dif }}}{N_{\text {total }}}
$$

$>$ Jukes-Cantor [Jukes and Cantor, 1969]

$$
d=-\frac{19}{20} \log \left(1-p * \frac{20}{19}\right)
$$

$>$ Kimura distance [Kimura, 1983]

$$
d=-\ln \left(1-p-0.2^{2}\right)
$$

$>$ Pairwise score using Dayhoff matrices

$$
d=\sum \frac{1-S_{i j}}{S_{i i}} * \frac{1-S_{i j}}{S_{j j}}
$$




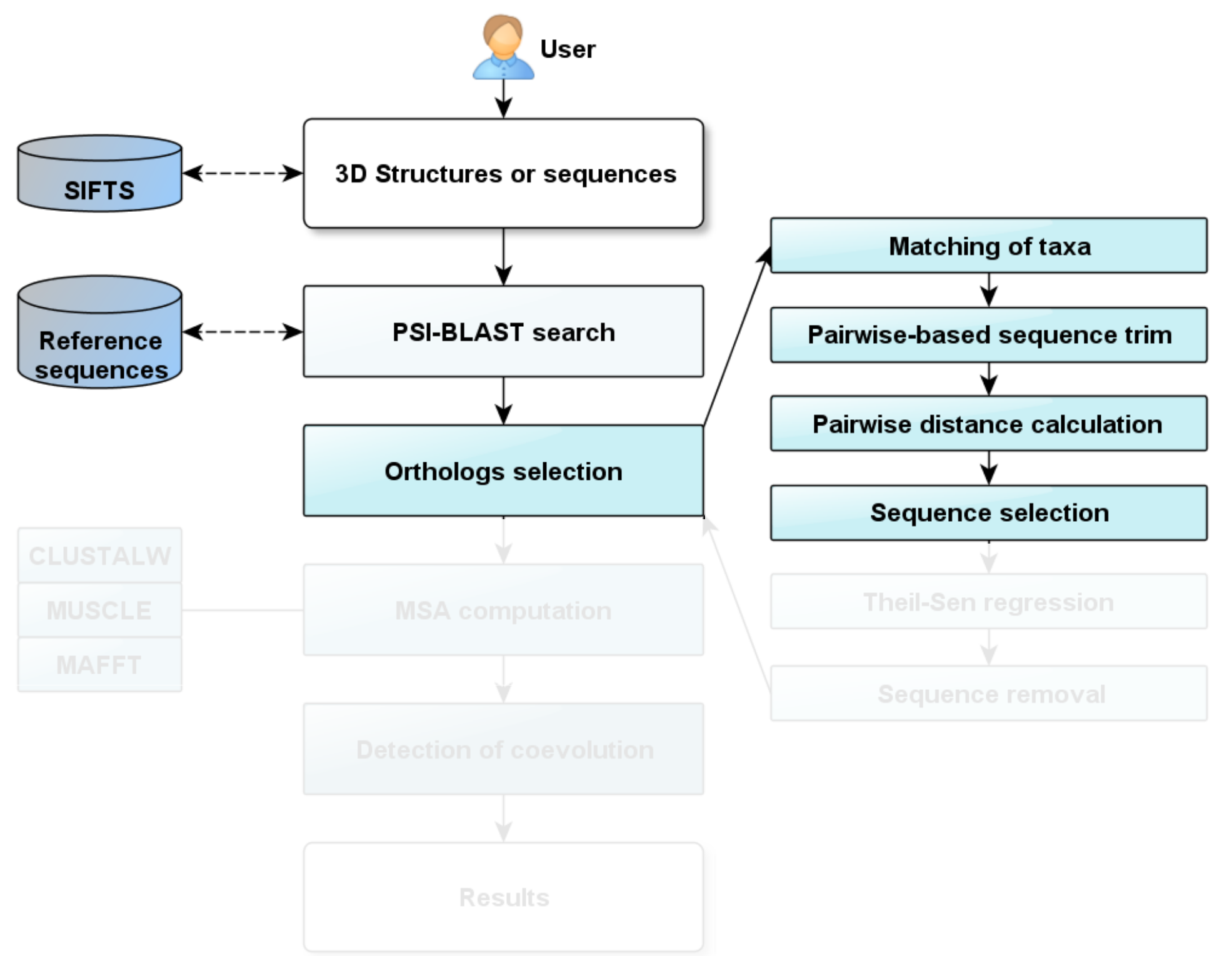




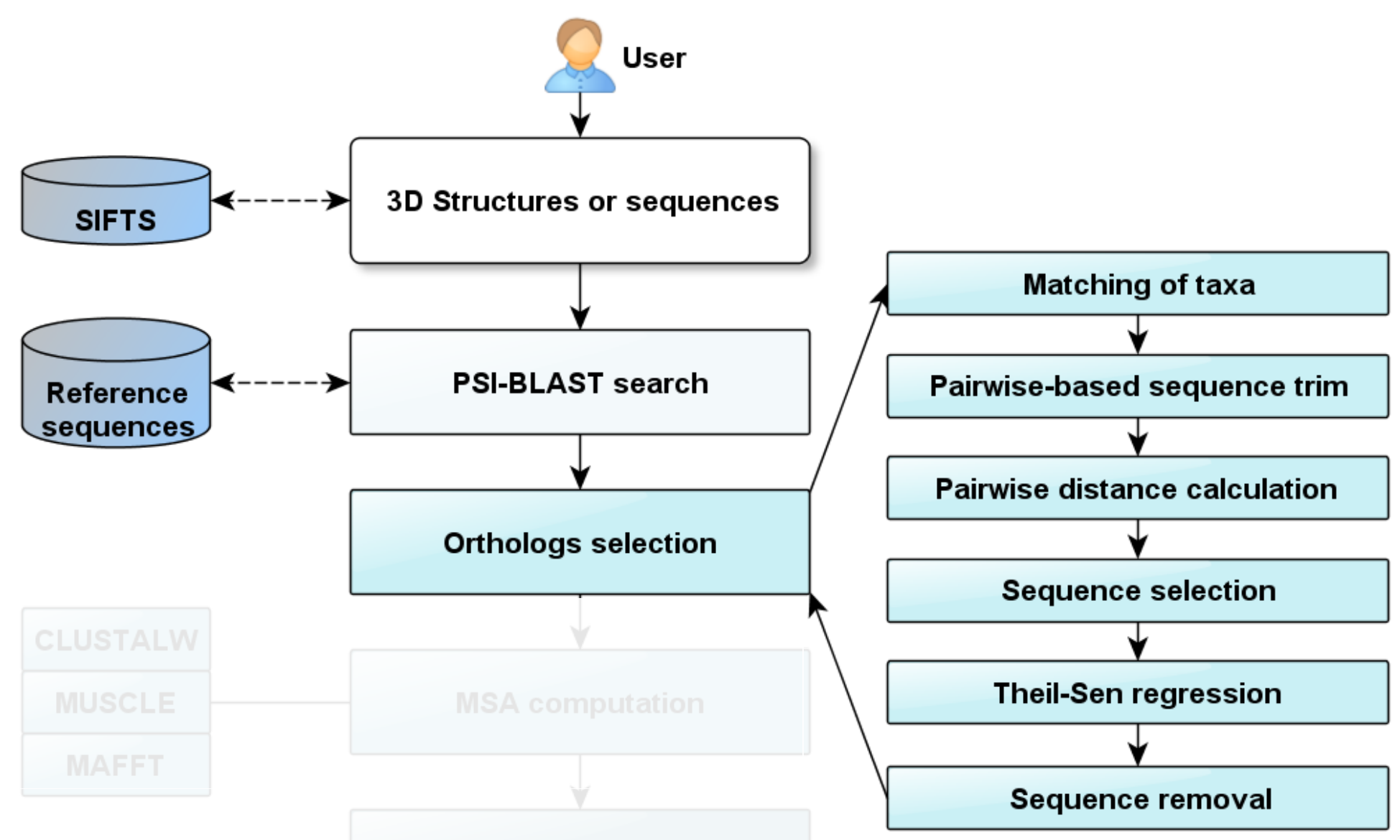


$>$ Median $m$ of the slopes $\left(y_{j}-y_{i}\right) /\left(x_{j}-x_{i}\right)$ determined by all pairs of sample points $\in(x, y)$, which have distinct $x$-coordinates [Theil, 1950] and [Sen, 1968]

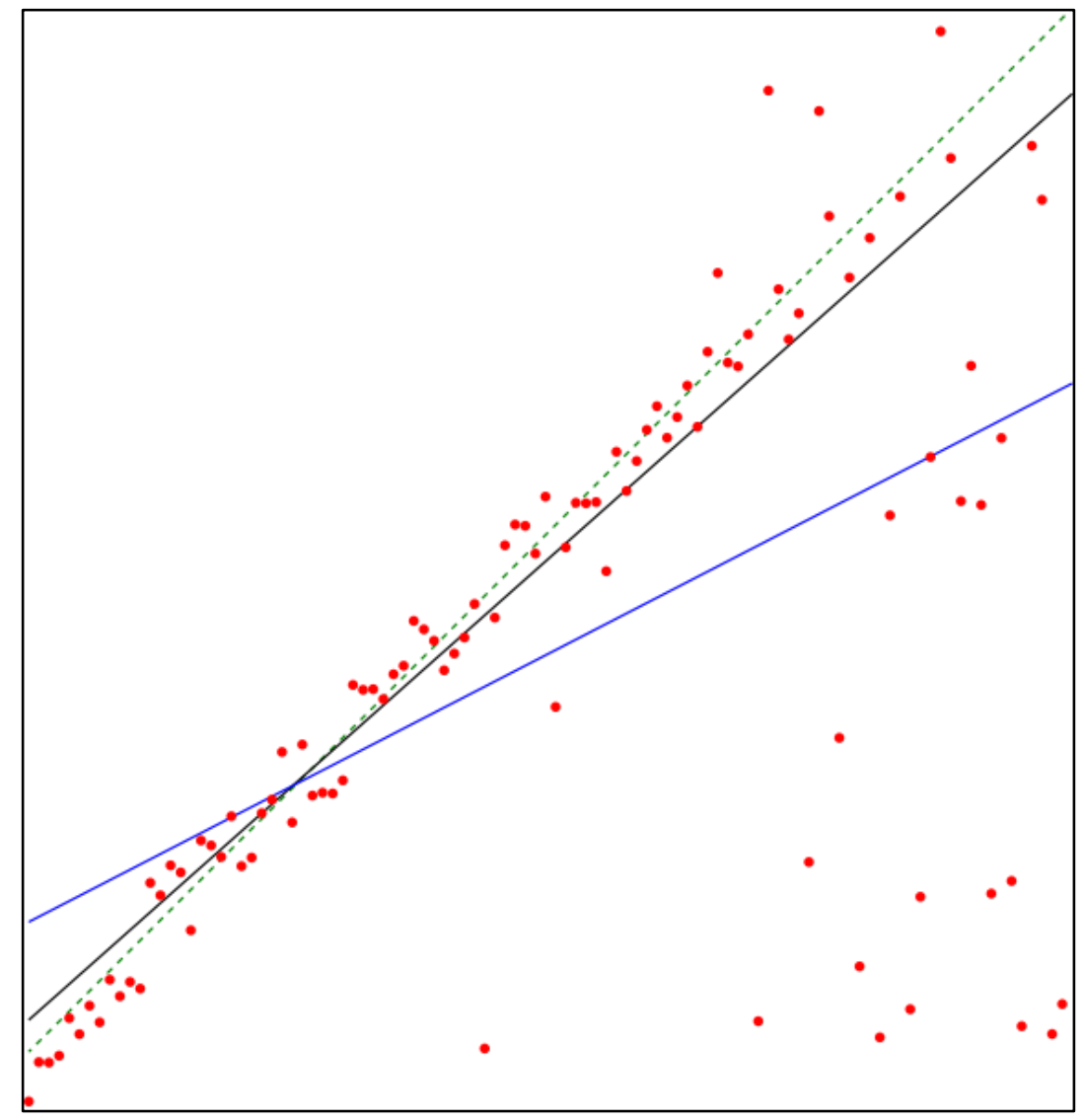




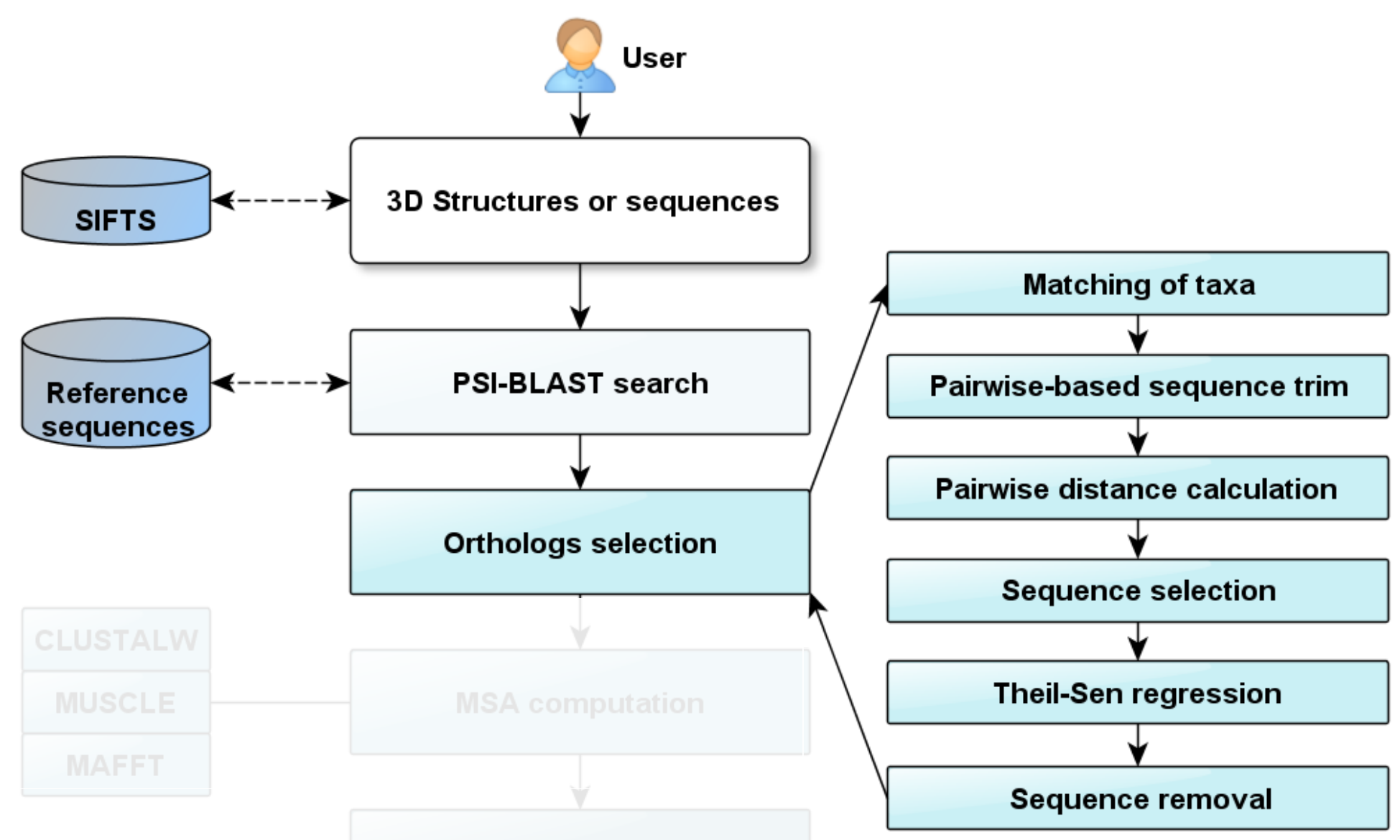




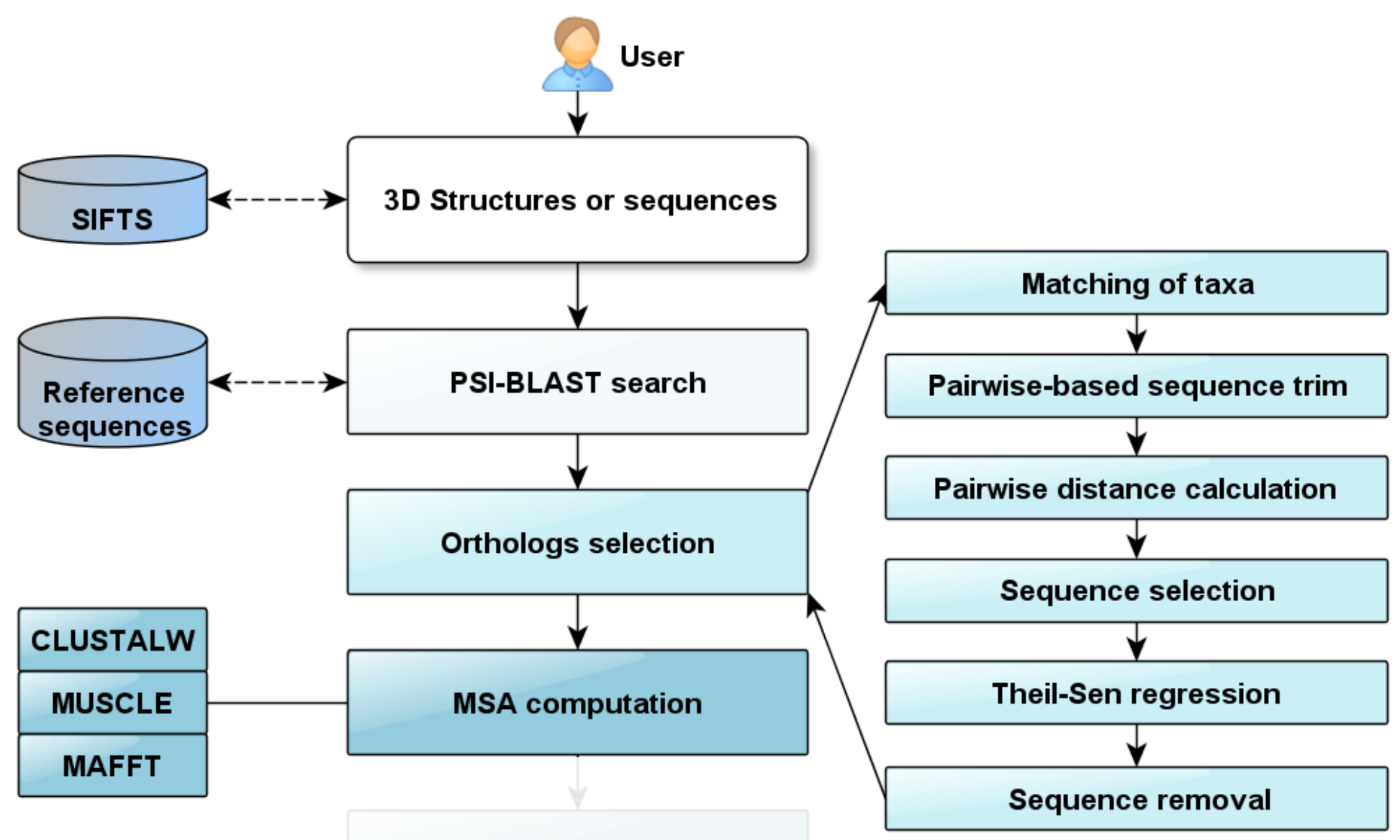




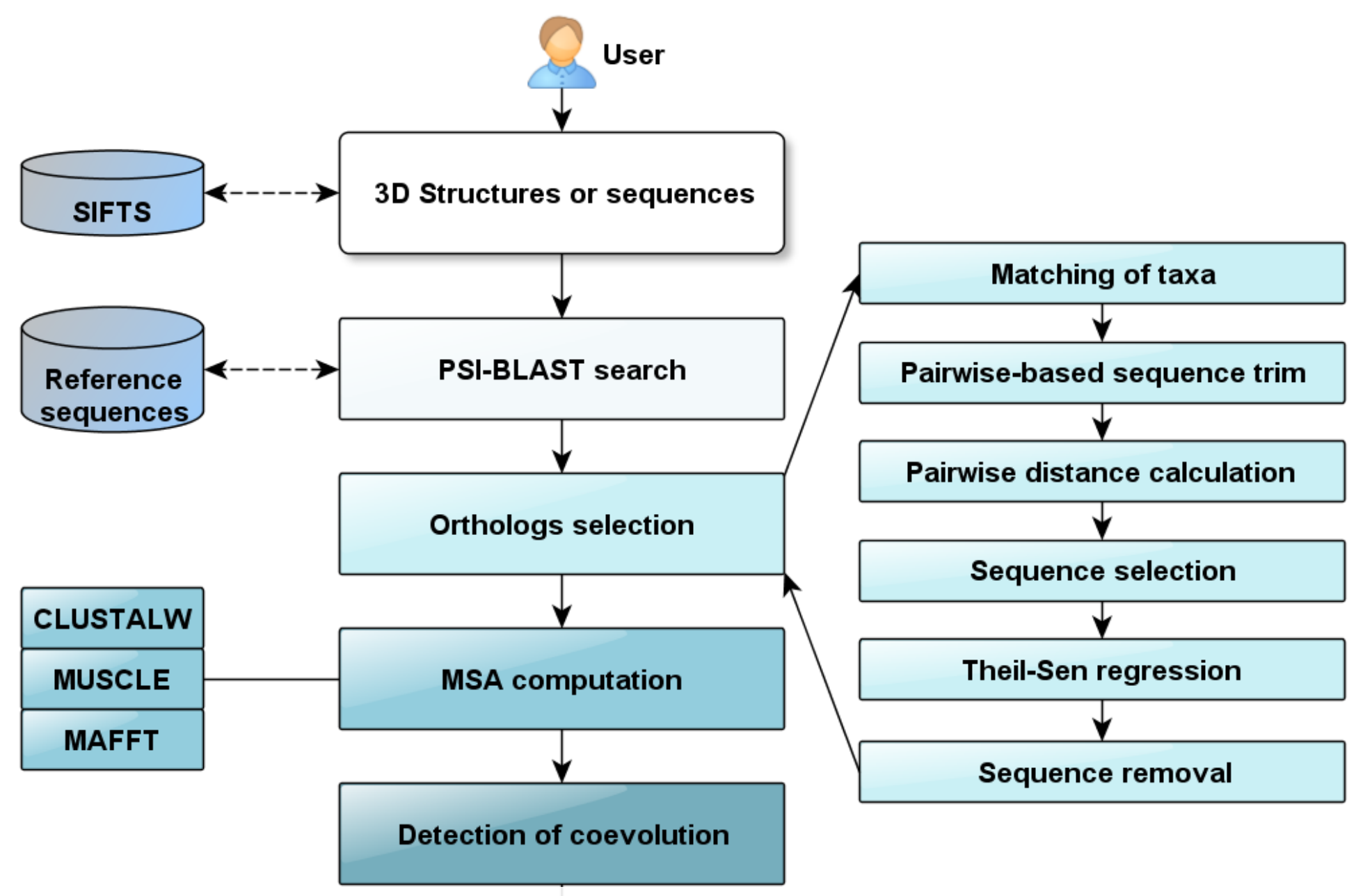


$>$ Contact Preferences, Volume Normalized (CPVN) [Glaser et al, 200I]

$>$ Contact PDB-derived Likelihood Matrix (CLM) [Singer et al, 2002]

$>$ Residue-residue Volume Normalized (VOL) [Esque et al, 2010]

$$
C M_{x, y}=\sum_{i}^{n} \sum_{j}^{n} \frac{S_{i j}}{n}
$$


> Pearson's correlation (Pearson) [Göbel et al, 1994]

D Spearman's rank correlation (Spearman) [Pazos et al, 1997]

D McLachlan Based Substitution Correlation (McBASC) [Fodor and Aldrich, 2004]

$>$ Quartets [Galitsky, 2002]

$$
C M_{x, y}=\frac{1}{N^{2}} \sum_{i} \sum_{j} \frac{W_{i j}\left(S_{x i j}-\left\langle S_{x}\right\rangle\right)\left(S_{y i j}-\left\langle S_{y}\right\rangle\right)}{\sigma_{x} \sigma_{y}}
$$

$>$ Observed Minus Expected Squared (OMES) [Kass and Horovitz, 2002]

$$
C M_{x, y}=\sum_{l}^{L} \frac{\left(N_{o b s}-\frac{C_{x i} C_{y j}}{N_{\text {valid }}}\right)^{2}}{N_{\text {valid }}}
$$


$>$ Mutual Information (MI) [Gloor et al, 2005]

$>$ MI by pair Entropy (MI/E) [Martin et al, 2005]

$>$ Row and Column Weighed MI (RCW MI) [Gouveia-Oliveira et al, 2007]

$$
M I_{x, y}=\sum_{i} \sum_{j} P\left(x_{i} y_{j}\right) \log \frac{P\left(x_{i} y_{j}\right)}{P\left(x_{i}\right) P\left(y_{j}\right)}
$$

> Statistical Coupling Analysis (SCA) [Lockless and Ranganathan, 1999]

$$
\Delta \Delta G_{x, y}=\sqrt{\sum_{i}\left(\ln P_{x \mid \delta y}^{i}-P_{x}^{i}\right)^{2}}
$$

> Explicit Likelihood of Subset Covariation (ELSC) [Dekker et al, 2004]

$$
\Lambda_{x}^{y}=\prod_{r}^{20} \frac{\left(\begin{array}{l}
N_{r, y} \\
n_{r, y}
\end{array}\right)}{\left(\begin{array}{l}
N_{r, y} \\
m_{r, y}
\end{array}\right)}
$$




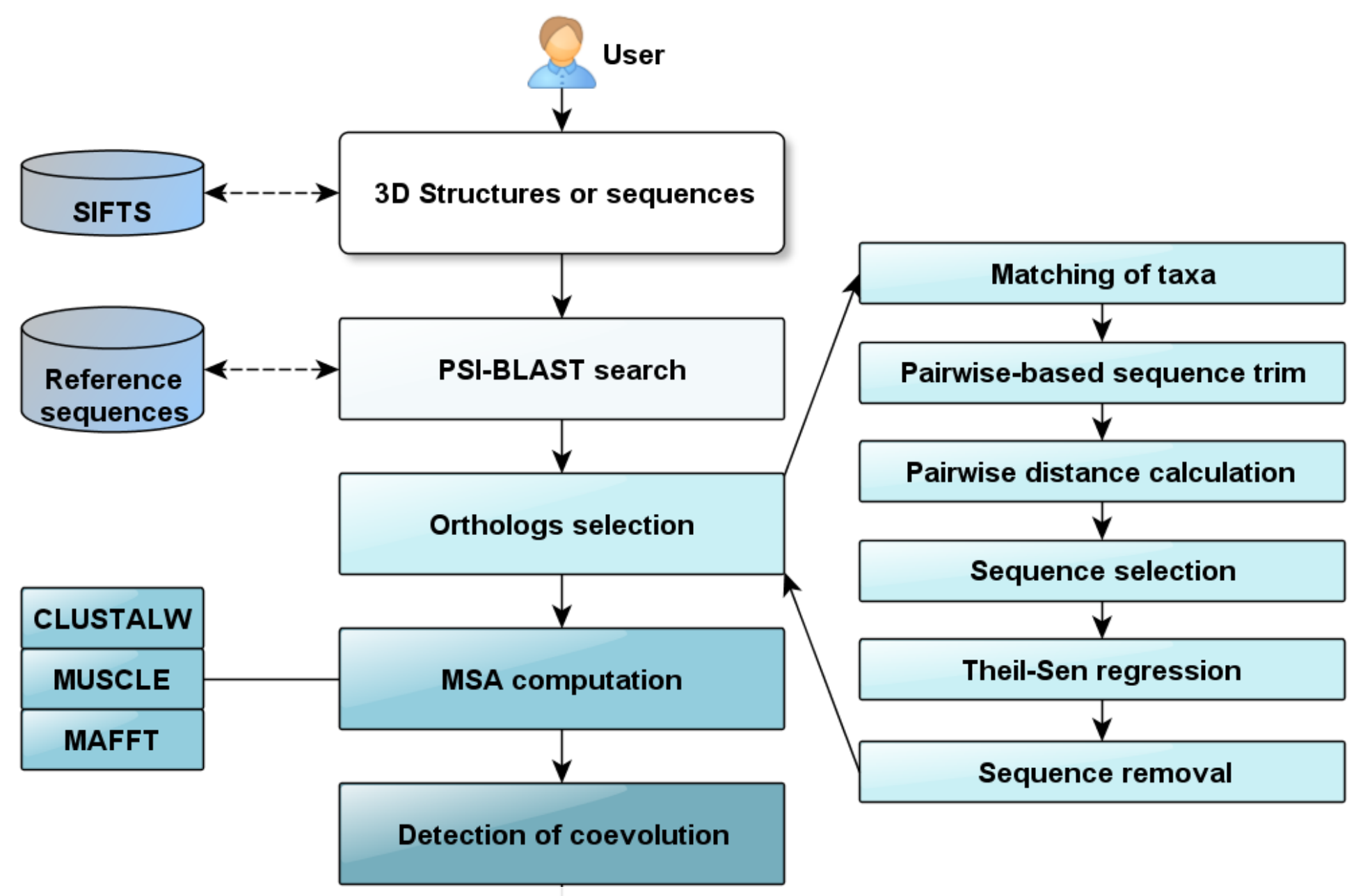




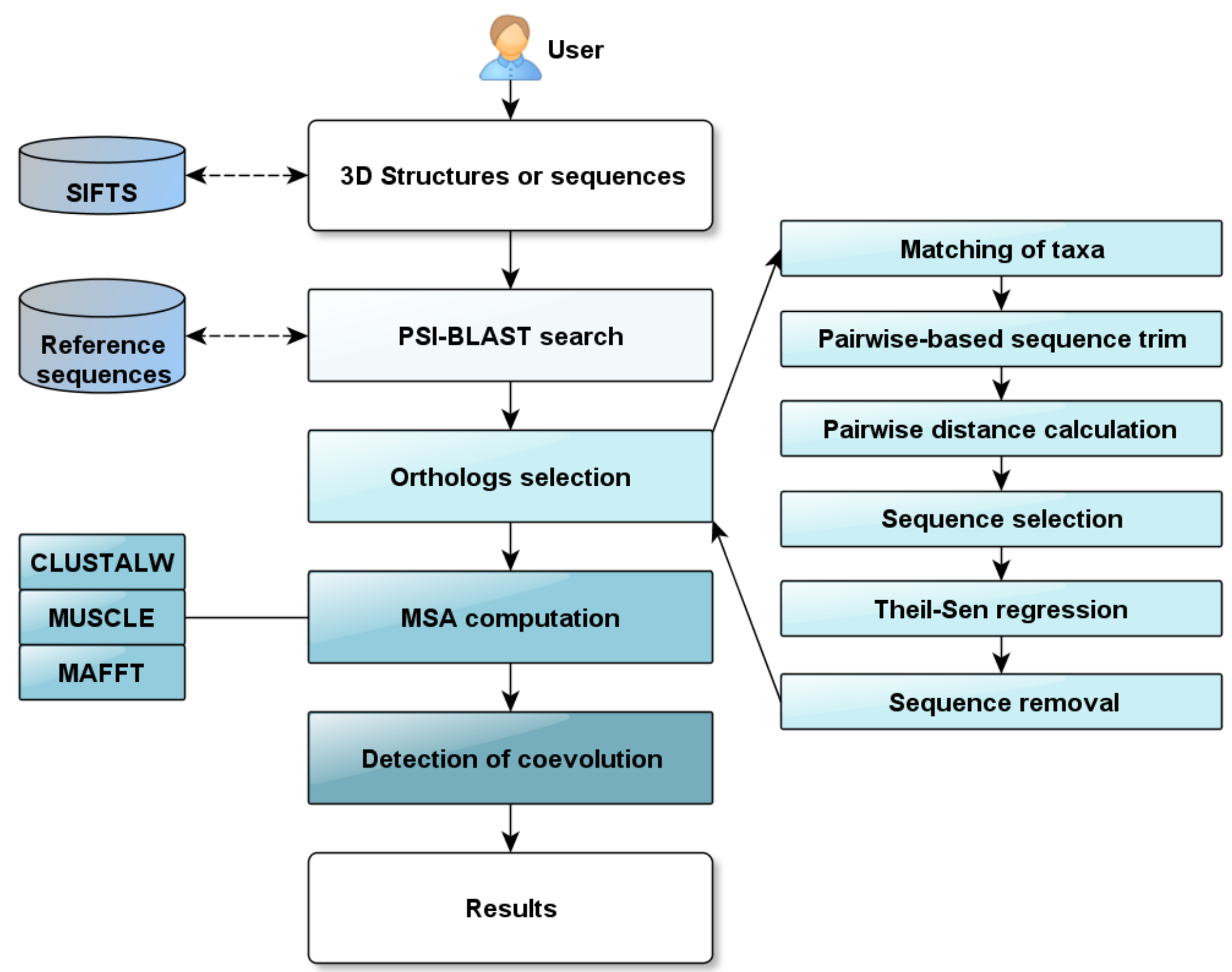


Datrix of coevolution scores and lists with the most significant coevolving residues

\begin{tabular}{|c|c|c|c|c|c|c|c|c|}
\hline & 1 & 2 & 3 & 4 & 5 & 6 & 7 & $x$ \\
\hline 1 & 0.12 & 0.23 & 0.11 & 0.01 & 0.02 & 0.21 & 0.04 & $\ldots$ \\
\hline 2 & 0.09 & 0.14 & 0.34 & 0.09 & 0.09 & 0.05 & 0.05 & $\ldots$ \\
\hline 3 & 0.00 & 0.20 & 0.07 & 0.05 & 0.06 & 0.14 & 0.04 & $\ldots$ \\
\hline 4 & 0.23 & 0.13 & 0.07 & 0.03 & 0.13 & 0.23 & 0.02 & $\ldots$ \\
\hline 5 & 0.04 & 0.00 & 0.14 & 0.21 & 0.10 & 0.05 & 0.01 & $\ldots$ \\
\hline 6 & 0.05 & 0.23 & 0.02 & 0.45 & 0.12 & 0.12 & 0.04 & $\ldots$ \\
\hline 7 & 0.12 & 0.01 & 0.01 & 0.02 & 0.29 & 0.30 & 0.04 & $\ldots$ \\
\hline$y$ & $\ldots$ & $\ldots$ & $\ldots$ & $\ldots$ & $\ldots$ & $\ldots$ & $\ldots$ & $\ldots$ \\
\hline
\end{tabular}

\begin{tabular}{|c|c|c|}
\hline Protein A & Protein B & Score \\
\hline 13 & 67 & 0.61 \\
\hline 14 & 187 & 0.59 \\
\hline 56 & 87 & 0.58 \\
\hline 79 & 34 & 0.56 \\
\hline 102 & 35 & 0.51 \\
\hline 178 & 35 & 0.50 \\
\hline$x$ & $y$ & $\ldots$ \\
\hline
\end{tabular}




\section{$>$ Histograms and heatmaps}
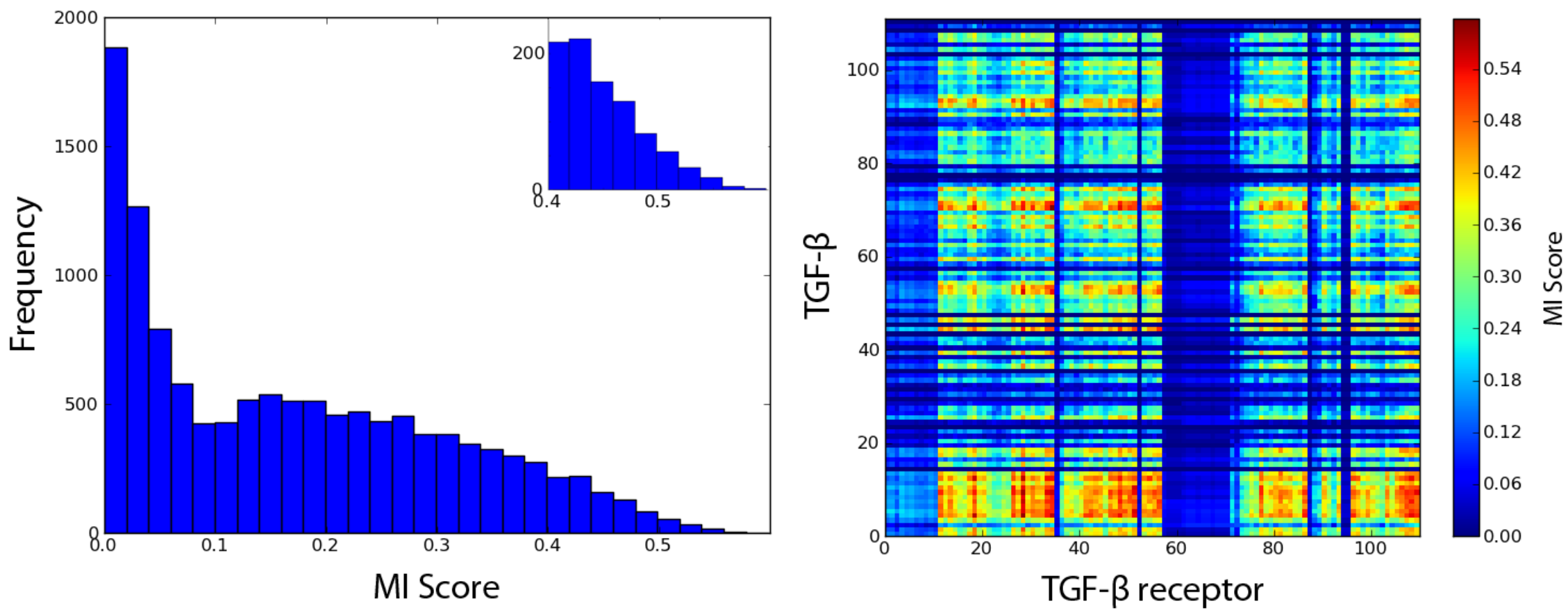
Pymol scripts for rapid visualization of 3D structures
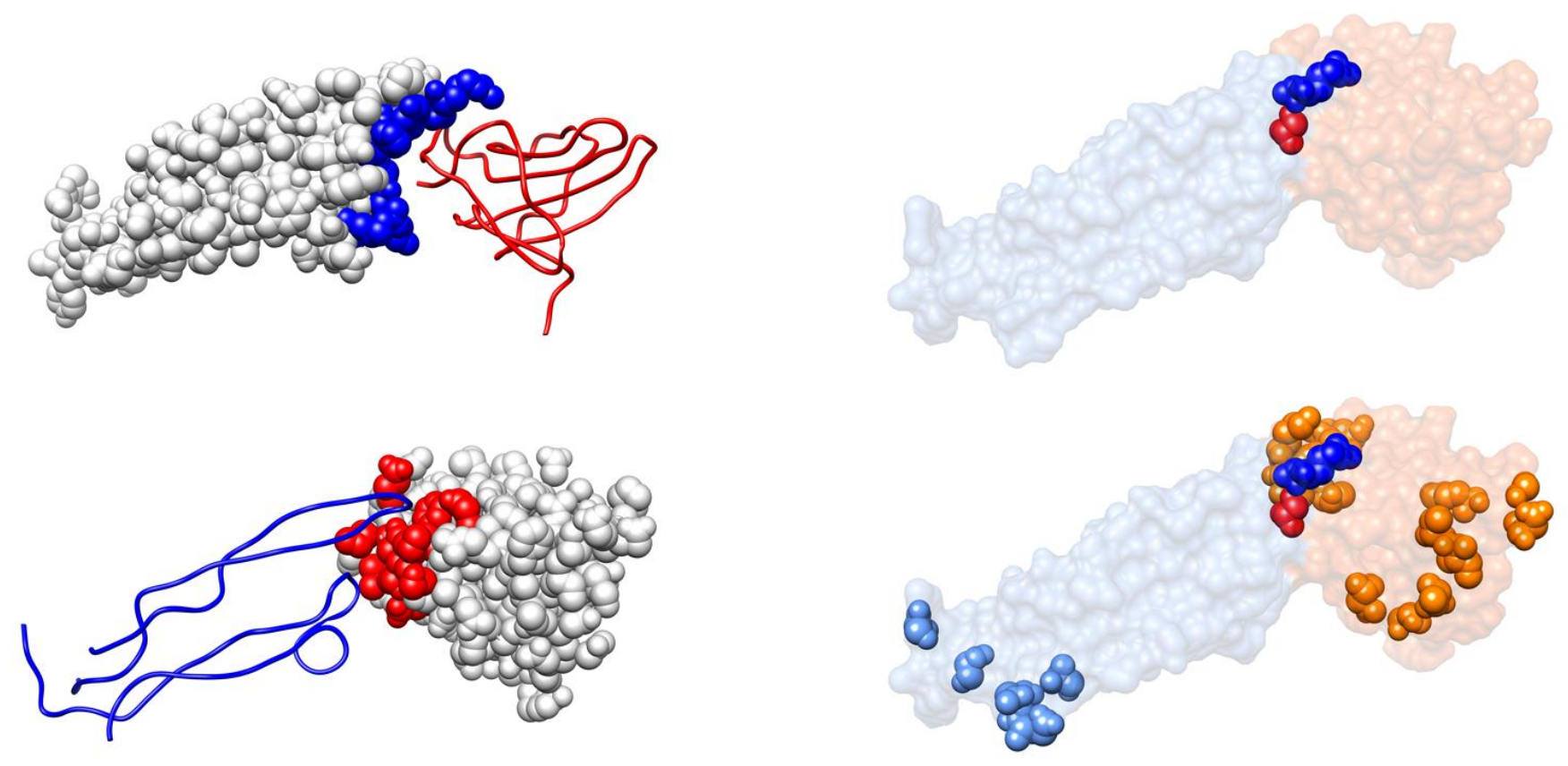
Protein complex TGF- $\beta 3 /$ TGF- $\beta$ receptor type II (I ktz)

- Most residues were at the surface level

- 3 out of 23 residues were at the interface

- 8 residues from TGF- $\beta 3$

- $\quad 15$ residues from TGB- $\beta$ receptor
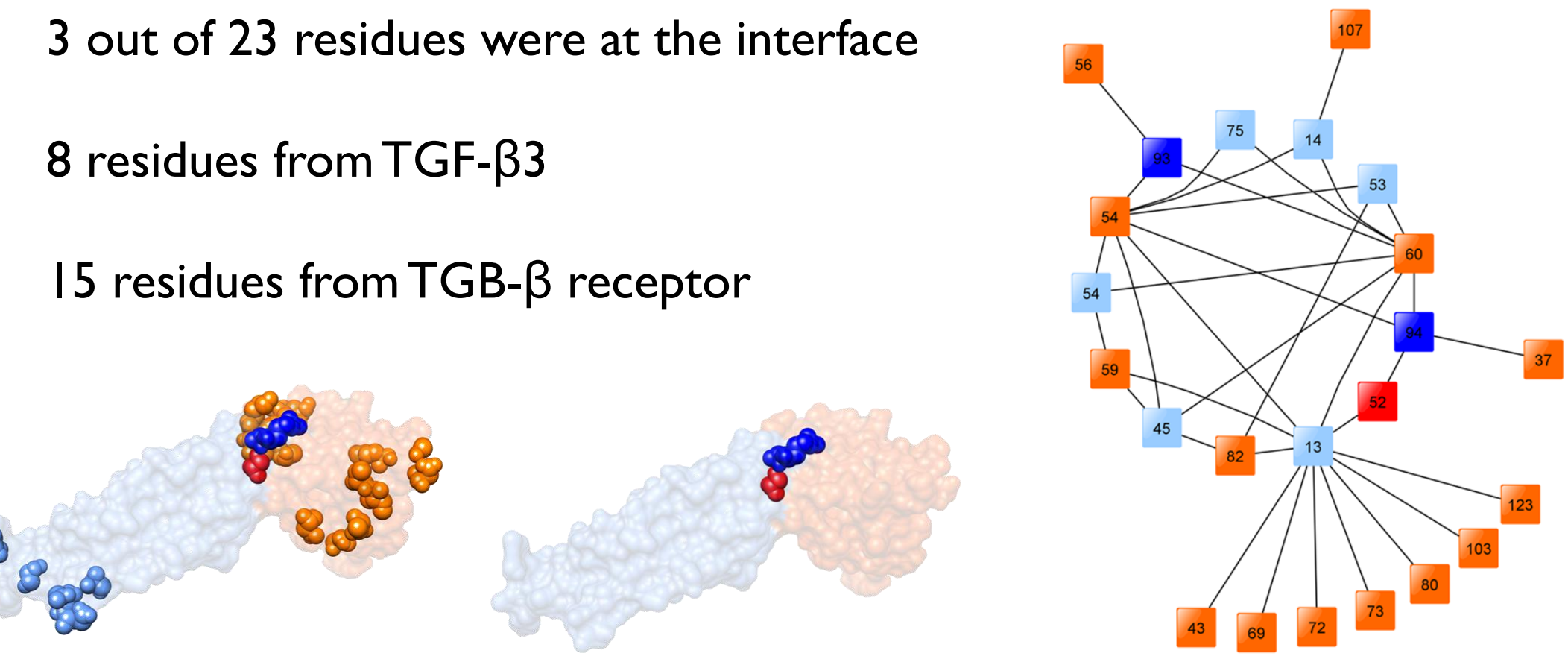
- Possible pairs of contacts $=11772$

- Tested contacts $=120$

- Reduced the search space to $0.01 \%$ of possible contact points

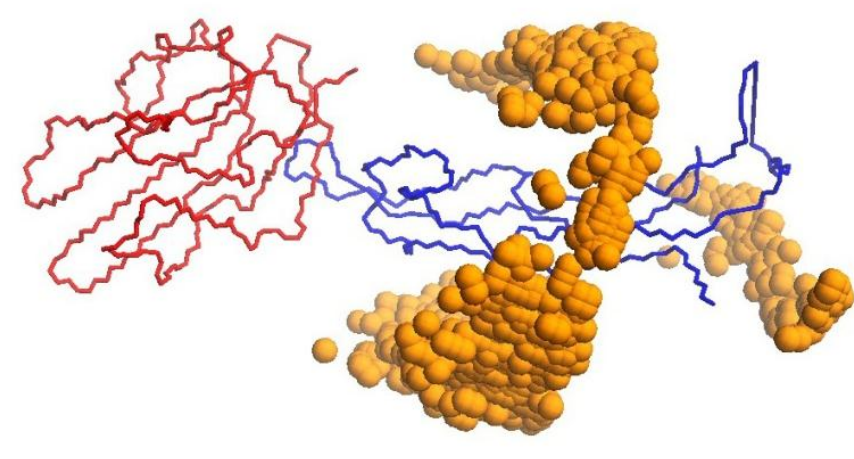

Difficult complex to model 
- Possible pairs of contacts $=11772$

- Tested contacts $=120$

- Reduced the search space to $0.01 \%$ of possible contact points

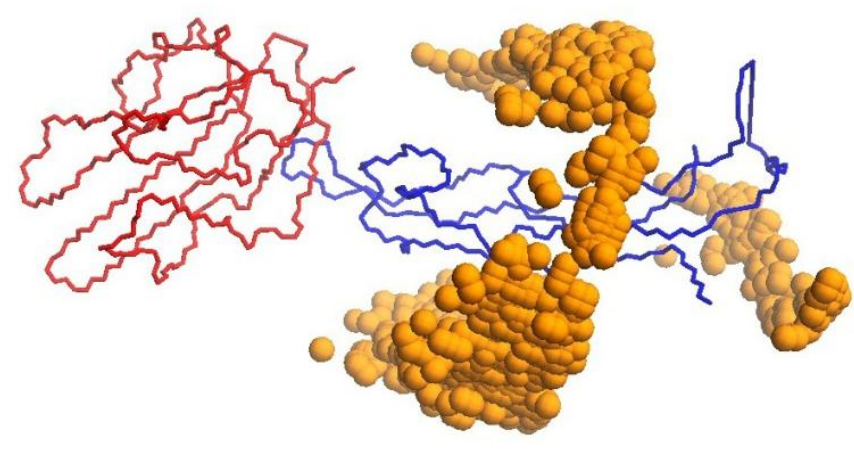

Difficult complex to model

$>$ Given the complexity of protein-protein docking, finding even only one positive interface contact can help constraint the search space and improve the accuracy of constrained docking algorithms such as BiGGER [Palma et al, 2000] 
$>$ Set of tools for the study of inter-protein coevolution and interaction 
$>$ Set of tools for the study of inter-protein coevolution and interaction

$>$ Implements the classic workflow with extended capabilities 
$>$ Set of tools for the study of inter-protein coevolution and interaction

D Implements the classic workflow with extended capabilities

$>$ Automates access to remote databases and third-party applications 
$>$ Set of tools for the study of inter-protein coevolution and interaction

$>$ Implements the classic workflow with extended capabilities

$>$ Automates access to remote databases and third-party applications

S Simplifies the coevolution analysis and the interpretation of results 
$>$ Set of tools for the study of inter-protein coevolution and interaction

$>$ Implements the classic workflow with extended capabilities

$>$ Automates access to remote databases and third-party applications

S Simplifies the coevolution analysis and the interpretation of results

$>$ Implemented in Python and platform independent 
$>$ Set of tools for the study of inter-protein coevolution and interaction

$>$ Implements the classic workflow with extended capabilities

$>$ Automates access to remote databases and third-party applications

S Simplifies the coevolution analysis and the interpretation of results

$>$ Implemented in Python and platform independent

$>$ Open source and public domain 
$>$ Set of tools for the study of inter-protein coevolution and interaction

$>$ Implements the classic workflow with extended capabilities

$>$ Automates access to remote databases and third-party applications

S Simplifies the coevolution analysis and the interpretation of results

$>$ Implemented in Python and platform independent

$>$ Open source and public domain

$>$ Source code at https://github.com/fmadeira/pycoevol 
$>$ Survey which method is better suited for the identification of interface contact points using a large protein complex dataset 


\section{$>$ Thanks for your attention!}

Fábio Madeira - fmadeira@campus.fct.unl.pt

CENTRIA-DI, Faculdade de Ciências e Tecnologia 